\title{
COMPARATIVE STUDY BETWEEN INTRAMEDULLARY FIXATION AND ARTHROPLASTY FOR THE MANAGEMENT OF UNSTABLE TROCHANTERIC FRACTURE IN ELDERLY
}

\author{
Ibrahim El Ganzoury*, Osama Farag*, Amr Ahmed*, Ahmad Salem*, \\ David Gergis Rady**
}

\author{
* Orthopedic Surgery \\ Department, Faculty of Medicine, \\ Ain Shams University \\ **Orthopedic Surgery \\ Department, Nasr City Hospital \\ Corresponding author \\ David Gergis Rady \\ Mobile: 01001158807 \\ E.mail:: \\ dr_davidrady@yahoo.com; \\ Received: $15 / 10 / 2020$ \\ Accepted: 19/11/2020
}

Online ISSN: $\mathbf{2 7 3 5 - 3 5 4 0}$

\begin{abstract}
Background: Intertrochanteric fractures involve those occurring in the region extending from the extra capsular basilar neck region to the region along the lesser trochanter proximal to the development of the medullary canal, these fractures account for forty percent of proximal femoral fractures in elderly.
\end{abstract}

Aim of the Work: is to compare intramedullary fixation and hip arthroplasty in treatment of unstable trochanteric fracture in elderly in terms of surgical techniques, clinical and radiological outcome, complications, functional outcome and patient satisfaction.

Patients and Methods: The thesis is a prospective comparative randomized study between PFN and Hemiarthroplasty for the treatment of unstable trochanteric fractures in elderly. Patients were followed up at 1, 3, 6, 12 month postoperative, clinical and radiological data collected and documented starting from perioperative data (operative time, blood loss, transfusion).

Results: We compared intramedullary fixation and hip arthroplasty in treatment of unstable, comminuted trochanteric fracture in elderly in terms of surgical techniques, clinical and radiological outcome, complications, functional outcome. We did our best to execute it in an objective unbiased scientific manner by allocating patients randomly into two groups using closed opaque envelops. This was confirmed by the mean personal data (Age, sex), side of the fracture, pre-existing comorbidities, and fracture type according to AO classification, both groups were comparable, with no significant difference. Comparison of operative data showed significant difference in operative time, mean operative time was [78.4 min for group $1 \mathrm{Vs} 112.6$ min for group 2], favoring group 1 as less operative time.

Conclusion: Hemiarthroplasty could be valid option in management of unstable trochanteric fractures in elderly, giving the advantage of early full weight bearing, yet it is more technically demanding, require higher surgical experience.

Keywords: Intramedullary Fixation, Arthroplasty, Unstable Trochanteric Fracture

\section{INTRODUCTION}

Intertrochanteric fractures involve those occurring in the region extending from the extracapsular basilar neck region to the region along the lesser trochanter proximal to the development of the medullary canal, these fractures account for forty percent of proximal femoral fractures in elderly ${ }^{[1]}$.

They are the most frequently operated fracture type in elderly, having the highest 
postoperative fatality rate of surgically treated fractures, according to its configuration, intertrochanteric fractures can be classified to stable or unstable fractures ${ }^{[2]}$.

Many studies concluded that stable intertrochanteric fracture can be treated with dynamic hip screw (DHS) with good outcome and lower complication rate ${ }^{[3][4]}$.

Unstable trochanteric fractures in elderly are challenging due to bad bone quality and associated co-morbidities ${ }^{[5]}$, Goals of surgical management is to restore ambulation as early as possible. The importance of physician, hospital care, and geriatric co-management has successfully improved patient care while decreasing $\operatorname{cost}^{[6]}$.

Although the ideal treatment of these types of fractures is still controversial in elderly, Intra medullary fixation have shown mechanical advantages when compared to plate fixation, faster recovery and postoperative ambulation was observed. Although internal fixation is still the standard of treatment, it has been debated because of difficulty in reconstruction and incidence of loss of fixation in complex fractures. In such cases, prosthetic replacement is considered an alternative to fixation to restore early weigh bearing, and avoid mechanical failure ${ }^{[7]}$.

Low energy fall is associated with trochanteric fractures in elderly. Almost $90 \%$ of these injuries in geriatric patient occurs after simple fall due to the inverse relationship between advancing age and bone quality. Fall prevention remains crucial in preventing trochanteric fractures in elderly, and can be accomplished by exercise programs, vitamin $\mathrm{D}$, along with osteoporosis management $^{[8][9]}$.

\section{AIM OF THE WORK:}

The aim of this thesis is to compare intramedullary fixation and hip arthroplasty in treatment of unstable trochanteric fracture in elderly in terms of surgical techniques, clinical and radiological outcome, complications, functional outcome and patient satisfaction.

\section{PATIENTS AND METHODS}

\section{Study design:}

The thesis is a prospective comparative randomized study between PFN and Hemiarthroplasty for the treatment of unstable trochanteric fractures in elderly.

\section{Inclusion criteria:}

The study enrolled patients above 65 , both males and females who were diagnosed with an isolated, unstable trochanteric fracture. The classification used is the AO classification, whereas Type A2 (A2.2, A2.3) and type A3 (A3.1,A3.2,A3.3) were included.

\section{Exclusion criteria:}

The study excluded patients below 65years, stable fractures (AO type 31A1). Polytrauma, patients with pathological fractures, as these parameters will influence method of treatment, and will affect the follow up and the outcome.

\section{Methods:}

Sample size was calculated using STATA program, setting the type- 1 error $(\alpha)$ at $5 \%$ and power at $80 \%$. Result from previous study (Ozkayin et al, 2015) showed that the 1 year post-operative HHS among Fixation group was $75.95 \pm 7.34$ compared to $68.44 \pm 10.5$ among arthroplasty group. Based on this, 25cases per group (50 TOTAL) were assigned for the study, the 50 Patients were randomized into two group via sealed opaque envelopes, 25 patient in each group. 31 males and 19 females. Group one (included $16 \mathrm{M}$ and $9 \mathrm{~F}$ ) underwent intramedullary fixation of the fracture using PFN, whereas group two (included $15 \mathrm{M}$ and $10 \mathrm{~F})$ were managed by Hemiarthroplasty, either cemented or cementless according to 
dorr type, 19 patients were treated with cemented stem, whereas cementless stems were used in 6 patients.

\section{Follow up and data collection:}

Patients were followed up at 1, 3, 6, 12 month postoperative., clinical and radiological data collected and documented starting from perioperative data (operative time, blood loss, transfusion). Comparison between the two groups were made at 12 month postoperative.

\section{Outcome measures:}

\section{Clinical outcome:}

The primary outcome measure of the patient were based on Harris Hip score (H.H.S). It was developed in 1969 to evaluate post traumatic arthritis of the hip. It has been validated for measurement of clinical outcome of proximal femoral fractures in elderly.

H.H.S is a score of 100 points (higher score $=$ better function). It consist of 4 items (pain 44 points, function 47 points, absence of deformity 4 points, ROM 5 points).

The questionnaire consist of 8 questions: 1 for pain and 7 for function, 2 observer measures: for R.O.M and absence of deformity, the secondary outcome measure was the incidence of complications in both the groups.

\section{Radiological outcome:}

Postoperative $\mathrm{x}$ ray pelvic AP with both hips, lateral view of the affected hip for both groups. The following data were collected:

For group one (PFN): union rate, metal failure, screw cut through, cut out, malunion, heterotopic ossification (H.O)

For group two (Hemiarthroplasty): Implant position, incidence of loosening, subsidence, trochanteric nonunion, H.O.

\section{Data Management and Analysis:}

The collected data were revised, coded, tabulated and introduced to a PC using Statistical package for Social Science (IBM Corp. Released 2011. IBM SPSS Statistics for Windows, Version 20.0. Armonk, NY: IBM Corp). Data were presented and suitable analysis was done according to the type of data obtained for each parameter. P- value: level of significance: $\mathrm{P}>0.05$ : Non significant (NS), $\mathrm{P}<0.05$ : Significant (S).

\section{RESULTS}

Table (1): Comparison between the 2 groups as regard personal and clinical characteristics

\begin{tabular}{|c|c|c|c|c|c|c|c|}
\hline & & \multicolumn{4}{|c|}{ Group } & \multirow[t]{3}{*}{$\mathrm{P}$} & \multirow[t]{3}{*}{ Sig } \\
\hline & & \multicolumn{2}{|c|}{ Fixation } & \multicolumn{2}{|c|}{ Arthroplasty } & & \\
\hline & & Mean & $\pm \mathrm{SD}$ & Mean & $\pm \mathrm{SD}$ & & \\
\hline \multicolumn{2}{|c|}{ Age } & 73.84 & 7.40 & 74.20 & 6.21 & $0.853^{\ddagger}$ & NS \\
\hline \multirow[t]{2}{*}{ Sex } & Male & 16 & $64.0 \%$ & 15 & $60.0 \%$ & \multirow[t]{2}{*}{$0.771^{*}$} & \multirow[t]{2}{*}{ NS } \\
\hline & Female & 9 & $36.0 \%$ & 10 & $40.0 \%$ & & \\
\hline \multirow[t]{2}{*}{ comorbidties } & No & 5 & $20.0 \%$ & 7 & $28.0 \%$ & \multirow[t]{2}{*}{$0.508 *$} & \multirow[t]{2}{*}{ NS } \\
\hline & Yes & 20 & $80.0 \%$ & 18 & $72.0 \%$ & & \\
\hline \multirow[t]{2}{*}{ Side } & Right & 17 & $68.0 \%$ & 14 & $56.0 \%$ & \multirow[t]{2}{*}{$0.382^{*}$} & \multirow[t]{2}{*}{ NS } \\
\hline & Left & 8 & $32.0 \%$ & 11 & $44.0 \%$ & & \\
\hline \multirow[t]{2}{*}{ Fracture type } & $\mathrm{A} 2$ & 16 & $64.0 \%$ & 20 & $80.0 \%$ & \multirow[t]{2}{*}{$0.208 *$} & \multirow[t]{2}{*}{ NS } \\
\hline & A3 & 9 & $36.0 \%$ & 5 & $20.0 \%$ & & \\
\hline
\end{tabular}

$\$$ Student $\mathrm{t}$ test $*$ Chi-square tests 
Table (2): Comparison between the 2 groups as regard operative characteristics

\begin{tabular}{|c|c|c|c|c|c|c|c|}
\hline & \multicolumn{4}{|c|}{ Group } & \multirow{3}{*}{$\mathrm{P}$} & \multirow{3}{*}{ Sig } \\
\hline & & \multicolumn{2}{|c|}{ Fixation } & \multicolumn{2}{|c|}{ Arthroplasty } & & \\
\hline & & Mean & $\pm \mathrm{SD}$ & Mean & $\pm \mathrm{SD}$ & & \\
\hline \multicolumn{2}{|l|}{ Operative time } & 78.40 & 16.44 & 112.60 & 14.80 & $0.001^{\ddagger}$ & $\mathrm{HS}$ \\
\hline \multicolumn{2}{|l|}{ Blood loss } & 210.80 & 87.51 & 432.00 & 116.26 & $0.001^{\ddagger}$ & HS \\
\hline \multirow[t]{2}{*}{ Blood transfusion } & No & 22 & $88.0 \%$ & 17 & $68.0 \%$ & \multirow[t]{2}{*}{$0.088^{*}$} & \multirow[t]{2}{*}{ NS } \\
\hline & Yes & 3 & $12.0 \%$ & 8 & $32.0 \%$ & & \\
\hline
\end{tabular}

† Student $\mathrm{t}$ test $*$ Chi-Square Tests

Table (3): Comparison between fixation and arthroplasty groups in AO type (A 2) only as regard operative characteristics

\begin{tabular}{|c|c|c|c|c|c|c|c|}
\hline & \multicolumn{4}{|c|}{ Group } & \multirow{3}{*}{$\mathrm{P}$} & \multirow{3}{*}{ Sig } \\
\hline & & \multicolumn{2}{|c|}{ Fixation } & \multicolumn{2}{|c|}{ Arthroplasty } & & \\
\hline & & Mean & $\pm \mathrm{SD}$ & Mean & $\pm \mathrm{SD}$ & & \\
\hline \multicolumn{2}{|c|}{ Operative time } & 77.81 & 13.66 & 111.25 & 15.21 & $0.001 \%$ & HS \\
\hline \multicolumn{2}{|c|}{ Blood loss } & 231.25 & 72.74 & 432.50 & 130.06 & $0.001 \div$ & HS \\
\hline \multirow{2}{*}{$\begin{array}{c}\text { Blood } \\
\text { transfusion }\end{array}$} & No & 14 & $87.5 \%$ & 15 & $75.0 \%$ & \multirow[t]{2}{*}{$0.426^{* * *}$} & \multirow[t]{2}{*}{ NS } \\
\hline & Yes & 2 & $12.5 \%$ & 5 & $25.0 \%$ & & \\
\hline
\end{tabular}

\pm Student $\mathrm{t}$ test $\quad * *$ Fisher exact test

Table (4): Comparison between fixation and arthroplasty in (AO type A 3 only) as regard operative characteristics

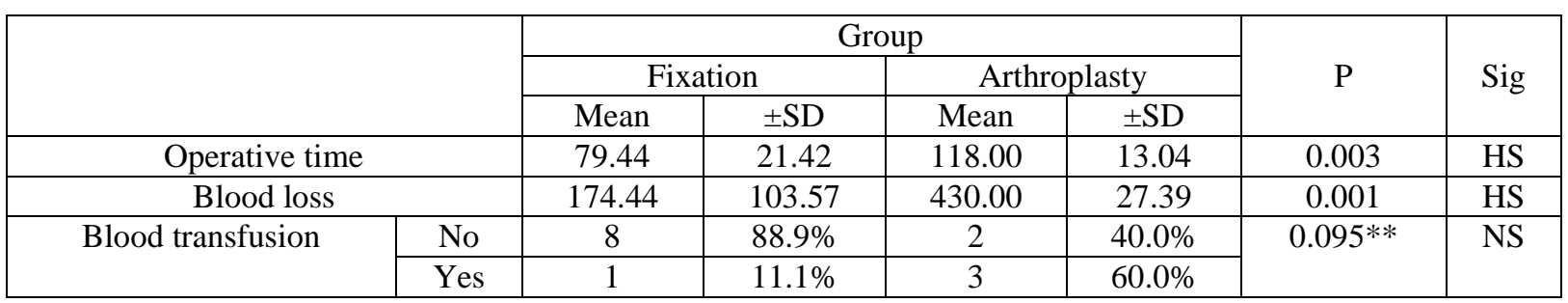

$\ddagger$ Student $\mathrm{t}$ test $* *$ Fisher exact test

Table (5): Comparison between fixation and arthroplasty (AO type 3 only) as regard post operative outcome and complications

\begin{tabular}{|c|c|c|c|c|c|c|c|}
\hline & \multicolumn{4}{|c|}{ Group } & \multirow{3}{*}{$\mathrm{P}$} & \multirow{3}{*}{ Sig } \\
\hline & & \multicolumn{2}{|c|}{ Fixation } & \multicolumn{2}{|c|}{ Arthroplasty } & & \\
\hline & & Mean & $\pm \mathrm{SD}$ & Mean & $\pm \mathrm{SD}$ & & \\
\hline \multicolumn{2}{|c|}{ Clinical outcome (HHS) } & 74.33 & 14.33 & 76.80 & 1.64 & $0.623 \%$ & NS \\
\hline \multirow[t]{2}{*}{ Radiological outcome } & Normal & 5 & $55.6 \%$ & 5 & $100.0 \%$ & \multirow[t]{2}{*}{$0.221 * *$} & \multirow[t]{2}{*}{ NS } \\
\hline & Abnormal & 4 & $44.4 \%$ & 0 & $0.0 \%$ & & \\
\hline \multirow[t]{2}{*}{ Complication } & No & 6 & $66.7 \%$ & 5 & $100.0 \%$ & \multirow[t]{2}{*}{$0.25^{* * *}$} & \multirow[t]{2}{*}{ NS } \\
\hline & Yes & 3 & $33.3 \%$ & 0 & $0.0 \%$ & & \\
\hline
\end{tabular}

$\$$ student $\mathrm{t}$ test $* *$ Fisher exact test

\section{DISCUSSION:}

Unstable trochanteric fractures in elderly are an important cause of mortality and morbidity. One of the limitation of internal fixation is prolonged immobilization required in the presence of osteoporosis and comminution in such cases ${ }^{[11]}$, thus treatment method should allow early, pain free mobilization to avoid complication of bed ridden ${ }^{[12]}$. Implant selection for unstable intertrochanteric fractures is still debatable. Following treatment with dynamic hip screw there is high prevalence of insufficient functionality, unacceptable shortening, screw cut out, varus collapse, and external 
rotation deformity in osteoporised geriatric patients ${ }^{[13 \& 14]}$. Arthroplasty or intramedullary hip nailing were recommended in these patients to allow for early loading without any collapse at the fracture area ${ }^{[10]}$.

Many studies suggested PFN rather than DHS for fixation of unstable fractures in elderly.

Lorich et al. in (2004) stated that a cephalomedullary implant has biomechanical advantage in the treatment of unstable intertrochanteric fracture because of its intramedullary placement and inhibition of excessive sliding. Cephalomedullary implants provide the functional advantage of early patient mobility at one or three months postoperatively $^{[15]}$.

Haidukewych et al. in (2009) summarized 10 simple tips to minimize failure and improve outcomes when treating intertrochanteric fractures of the hip. They are:

- Measurement of the Tip to Apex distance;

- No lateral wall; no use of hip screw;

- Know the unstable intertrochanteric fracture patterns and nail them;

- Beware of the anterior bow of the femoral shaft;

- When using a trochanteric entry nail, start slightly medial to exact tip of greater trochanter;

- Do not ream an unreduced fracture;

- Be cautious about the nail insertion trajectory and do not use a hammer to seat the nail;

- Avoid varus angulation of the proximal fragment, use the relationship between the tip of trochanter and center of femoral head;

- When nailing, lock the nail distally if the fracture is axially or rotationally unstable;

- Avoid fracture distraction when nailing.
They concluded that intramedullary nail fixation has become more common, even for fractures that are stable or nondisplaced ${ }^{[16]}$.

Hsu et al. in (2013) in their study on lateral femoral wall thickness did a retrospective study on 208 patients treated with DHS and barrel plate. The results showed that fracture of the lateral wall occurred in 42 patients (20\%). They found that lateral wall thickness was a reliable predictor of post-operative lateral wall fracture with a threshold value of $20.5 \mathrm{~mm}$ being a reliable predictor for secondary lateral wall fracture. They concluded that:

1) Applying a >20.5 mm threshold value for the use of a DHS can be expected to minimise the risk of post-operative lateral wall fracture; and 2) Intertrochanteric fracture with a lateral wall thickness <20.5 $\mathrm{mm}$ should not be treated with a DHS ${ }^{[16]}$.

Bryan Tan et al. in (2015) in their article on Morphology and fixation pitfalls of a highly unstable intertrochanteric fracture variant studied a variant of intertrochanteric fracture not wellcharacterised in the existing classification systems and concluded in their study that this intertrochanteric fracture variant is highly unstable with a high failure rate, loss of superolateral support rather than the medial calcar buttress is the main contributing factor to mechanical failure. Intramedullary nailing is more appropriate than extramedullary plating for such unstable fractures ${ }^{[17]}$.

Some literature reported failure rate up to $25 \%$ in severely comminuted trochanteric fracture with high incidence of proximal extension to the basicervical region, these fractures are mor prone to failure due to higher rate of non union, rotational instability, and persistant distraction in the fracture site. Videla, et al. in (2017) in a retrospective cohort study, they concluded that The incidence of concomitant ipsilateral extra- and intra-capsular fractures of the 
proximal femur must be taken into account in patients over 65 years of age. It is clinically relevant to identify these concomitant fractures in order to arrive at a correct diagnosis, which will facilitate preoperative planning and the choice of the best treatment to achieve a better outcome. Misdiagnosis may cause further problems, such as fixation failures, disability ${ }^{[18]}$.

In our study, we compared intramedullary fixation and hip arthroplasty in treatment of unstable, comminuted trochanteric fracture in elderly in terms of surgical techniques, clinical and radiological outcome, complications, functional outcome. We did our best to execute it in an objective unbiased scientific manner by allocating patients randomly into two groups using closed opaque envelops. This was confirmed by the mean personal data (Age, sex), side of the fracture, pre-existing comorbidities, and fracture type according to AO classification, (Tab: 2), both groups were comparable, with no significant difference.

Comparison of operative data (table: 3 ) showed significant difference in operative time, mean operative time was [78.4 min for group $1 \mathrm{Vs} 112.6 \mathrm{~min}$ for group 2 (Pvalue $=0.001)$, favoring group 1 as less operative time. Moreover, mean blood loss was significantly less in group 1,(210.8 ml) Vs. (432.0 ml) in group $2(\mathrm{P}$-value=0.001).

Regarding post-operative complication, clinical and radiological outcome there was no statistical significance between two groups (table: 4). Clinical outcome was

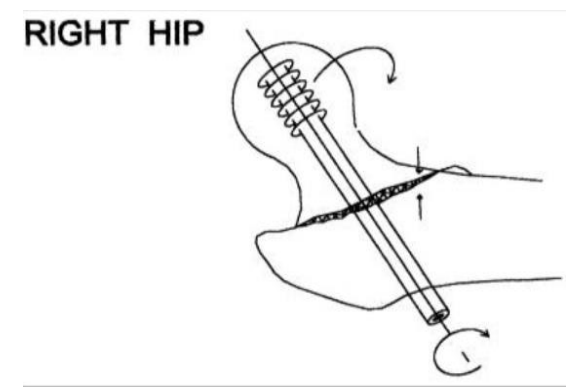

measured by HHS at one year postoperative, (73.8 for group 1 vs. 75.4 for group 2 with P-value 0.56).

Radiological outcome was defined normal for group 1 by restoration of limb length, rotation, alignment in coronal and axial plan, proper implant position, and normal fracture healing. For group 2, restoration of limb length, hip center of rotation, vertical, horizontal offset, anteversion, proper prosthesis component position. Normal radiological outcome was observed in 16 out of $25(64 \%)$ in group 1 vs. 20 out of $25(80 \%)$ in group 2, this was statistically insignificant (P-value= 0.208).

Abnormal radiological outcome was observed in 9 patients (36\%) in group 1, malunion was seen in $4(16 \%)$ of patient, two of them with varus collapse, fig(1), and screw cut-out $(8 \%)$, one with pure fracture collapse without varus, (4\%). HO occurred in one patient, fig (2), whose underwent open reduction in other one patient with left side (AO type 2.3)

A sagittal plan deformity was observed in form of anterior spike of the proximal fragment, this phenomena was observed by Mohan et al. ${ }^{[19]}$ there study assessed the effect of clockwise rotational torque on the fracture configuration of unstable trochanteric fracture, they compared 30 left side with 26 right side fractures, 11 of the 30 unstable left side showed anterior spiking, compared with none of the 26 right sided fractures. Fig $(3,4)$

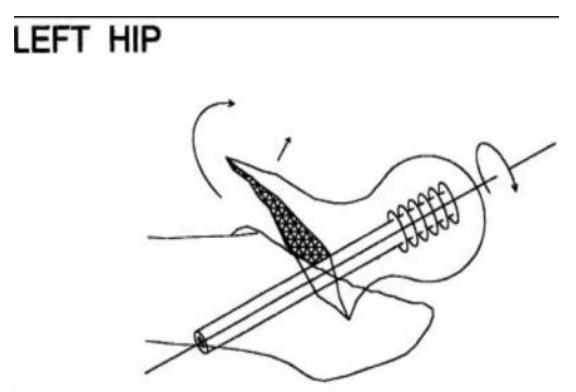

Fig (1): The effect of clockwise torque of the lag screw can cause loss of reduction, anterior spiking of the neck, in left side unstable IT fractures. Whereas with right sided injuries it causes compression of the fracture ${ }^{[19]}$. 

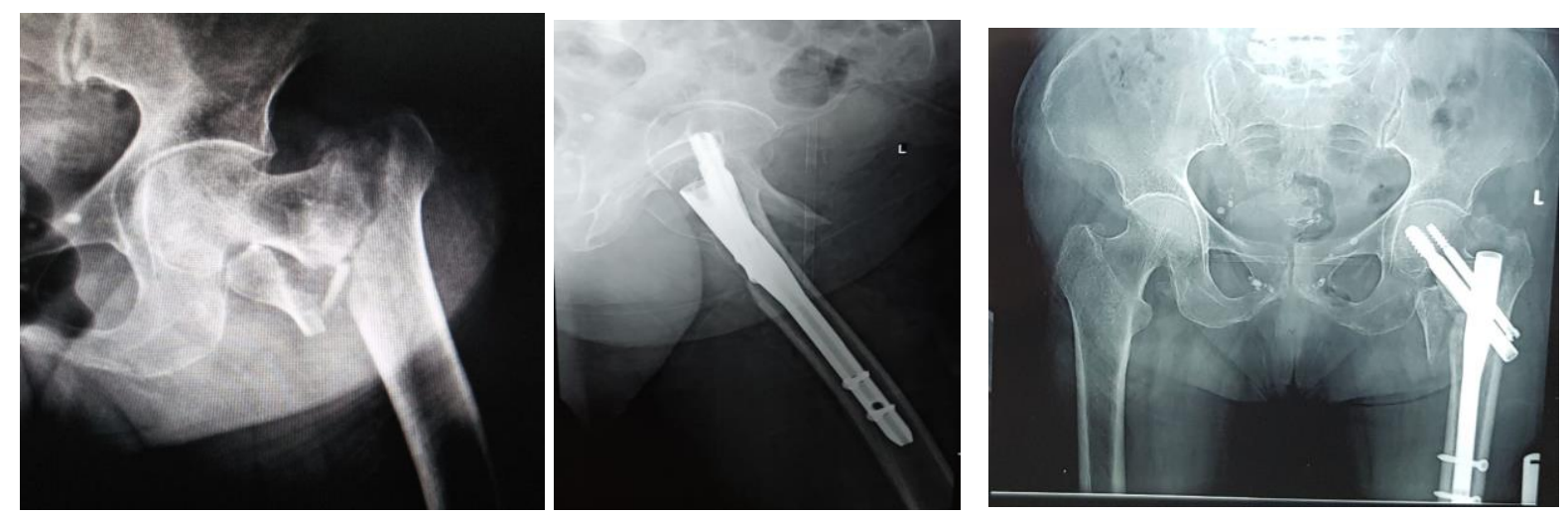

Fig (2): X ray of $69 y$ old female with unstable IT fracture left hip fixed with PFN, with lateral view showing anterior spiking of the neck fragment.

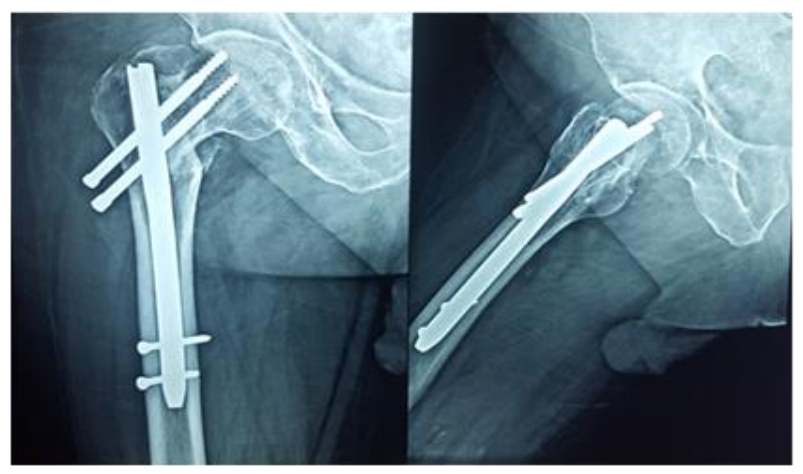

Fig (3): X ray of a $70 \mathrm{y}$ male patient, 1 year post-operative, with short recon. nail. Showing malunion with varus collapse

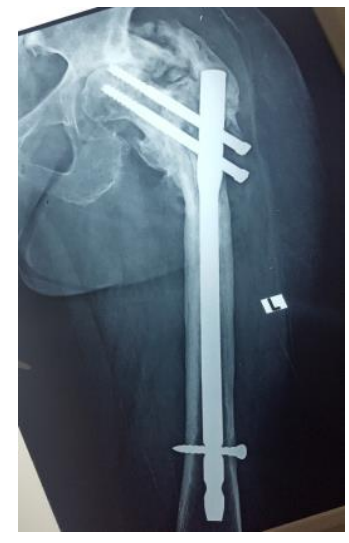

Fig (4): $X$ ray 1 year post-operative of $73 \mathrm{y}$. fem. With long PFN showing HO, varus malunion with $\mathrm{Z}$ effect.

These results suggest that hemiarthroplasty and PFN has comparable clinical outcome (at one year follow-up), and complication rate in management of unstable trochanteric fractures in elderly. However, hemiarthroplasty has relatively more operative time, blood loss. This can be interpreted by the complexity, technical demands of arthroplasty in the context of proximal comminution, making restoration of length and offset more challenging, moreover reattachment of the greater trochanter is necessary to restore abductor mechanism. PFN has more reoperation rate, but this was statistically insignificant. Also, more radiation exposure, this wad subjective, not measured in the study.

These data should be interpreted with caution and may need further research in the future with long term follow up and more 
specific selection of the more comminuted unstable AO type (31A2.3, 31A3.3).

Similar studies were conducted, comparing both options for management of unstable trochanteric fractures in elderly with variable data.

Parker and Handoll reported in a 2006 Cochrane Database review on two randomized controlled trials involving 148 patients, and reported that there was insufficient evidence to determine whether replacement arthroplasty has any advantage over internal fixation for extracapsular hip fractures ${ }^{[20]}$.

In 2005, Kim et al. performed a prospective randomized study of unstable intertrochanteric fractures in 58 elderly patients in which long-stem cementless calcar-replacement hemiarthroplasty was compared with a cephallomedullary nail, and the results showed that surgical time, blood loss, need for blood transfusion, and mortality rates were all significantly lower in the nail group. However, there were no significant differences between the two groups in terms of functional outcomes, hospital stay, time to weight bearing, and risk of complications ${ }^{[21]}$.

Bonnevialle et al. in (2011), present a prospective comparative observational study to validated the indication of arthroplasty in unstable trochanteric fracture in over-75 year-olds. Perioperative mortality and general complications rates were no higher than with nailing, despite elevated bleeding. Clinical results were better and earlier, and mechanical complications rates lower. Arthroplasty, however, should be performed by experienced operators, better able to avoid the pitfalls induced by loss of anatomic landmarks ${ }^{[7]}$.

Sahoo et al. (2015), in a multicentric prospective comparative study between cemented bipolar and PFN in management of unstable trochanteric fracture in elderly, concluded that Primary cemented hemiarthroplasty in unstable elderly hip fractures is reliable, technically simple and a safe procedure. It has a major advantage of allowing early mobilisation, immediate full weight bearing, rapid rehabilitation, shorter hospital stay and early return to work. Cemented arthroplasties are advantageous in non-union and high risk patients suffering from psychiatric illness in preventing periprosthetic dislocations and fractures ${ }^{[22]}$.

An interesting result was published by Özkayın et al. (2015). Although cases with cemented hemiarthroplasty achieved a better level of activity in the beginning, cases with proximal femoral nailing reached a comparable level of activity within a short period of time, faster than those treated with hemiarthroplasty, displaying a better level of activity in the end ${ }^{[23]}$. fig (6)
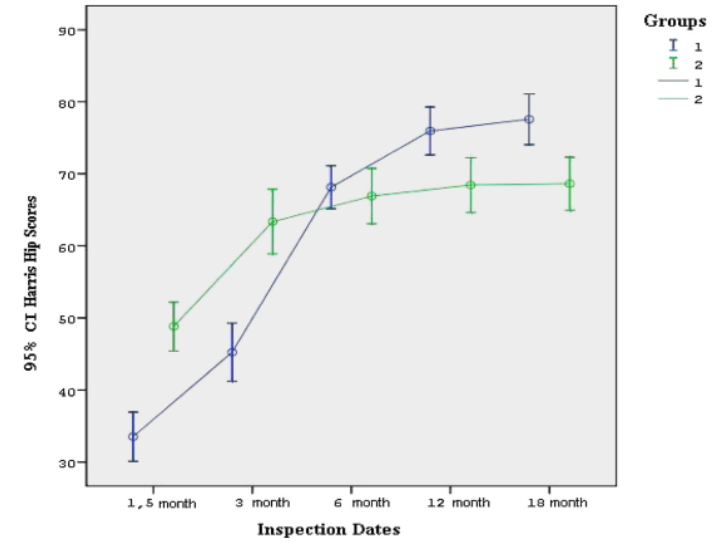

Diagram (1): Schematic drawing of the increase rate of Functional Harris Hip scores of both groups at inspection dates ${ }^{[23]}$. 
Boyuan Nie, et al. (2017), concluded that the use of arthroplasty can reduce implant-related complications and reoperation rate, but has no obvious statistical difference in terms of hospital stay. However, IMF results in reducing blood loss and transfusion requirement, shorter operation time, higher Harris hip score, and lower rate of 1-year mortality. The mainstay of treatment of IT hip fractures is internal fixation using IMF. In the absence of concrete evidence, arthroplasty should be undertaken with caution in carefully selected patient and surgeon should be aware of the increased complexity of doing the arthroplasty in these elderly patients. They suggest that arthroplasty may be considered as a primary treatment in patients with highly unstable factures with poor bone quality, ipsilateral hip arthritis, or other conditions with a higher risk for early failure ${ }^{[24]}$.

\section{Conclusion:}

At one year post-operatively, both PFN and hemiarthroplasty showed similar results in term of post-operative complication, radiological and clinical outcome. Although PFN was favoured by less operative time and blood loss, reoperation rate was higher but statistically insignificant. We concluded that hemiarthroplasty could be valid option in management of unstable trochanteric fractures in elderly, giving the advantage of early full weight bearing, yet it is more technically demanding, require higher surgical experience.

\section{REFERENCES}

1. Lindskog DM and Baumgaertner MR (2004): Unstable intertrochanteric hip fractures in the elderly. JAAOS-Journal of the American Academy of Orthopaedic Surgeons; 12(3): 179-190.

2. Evans EM (1949): The treatment of trochanteric fractures of the femur. The Journal of bone and joint surgery. British volume; 31(2): 190-203.
3. Bhandari M, Schemitsch E, Jönsson A, et al. (2009): Gamma nails revisited: gamma nails versus compression hip screws in the management of intertrochanteric fractures of the hip: a meta-analysis. Journal of orthopaedic trauma; 23(6): 460-464.

4. Parker MJ and Handoll HH (2010): Gamma and other cephalocondylic intramedullary nails versus extramedullary implants for extracapsular hip fractures in adults. Cochrane database of systematic reviews, 2010(9).

5. Bonnevialle P and Féron JM (2003): Les fractures du sujet âgé de plus de 80ans. Rev Chir Orthop, 89: S129-S182.

6. Feliciano D and Rasmussen $\mathrm{T}$ (2015): Skeletal Trauma: Basic Science, Management, and Reconstruction. $3^{\text {rd }}$ edition ed. Intertrochanteric Hip Fractures, ed. M.P. Leslie and M.R. Baumgaertner. Vol. chapter 55. 2015: Elsevier.

7. Bonnevialle P, Saragaglia D, Ehlinger M, et al. (2011): Trochanteric locking nail versus arthroplasty in unstable intertrochanteric fracture in patients aged over 75 years; 97(6): S95-S100.

8. Baker SP and Harvey AH (1985): Fall injuries in the elderly; 1(3): 501-512.

9. Guo JL, Tsai YY, Liao JY, et al. (2014): Interventions to reduce the number of falls among older adults with/without cognitive impairment: an exploratory meta-analysis; 29(7): 661-669.

10. Hardy DC, Descamps PY, Krallis P, et al. (1998): Use of an intramedullary hip-screw compared with a compression hip-screw with a plate for intertrochanteric femoral fractures. A prospective, randomized study of one hundred patients; 80(5): 618-30.

11. Wolfgang GL, Bryant MH, O'Neill JP et al. (1982): Treatment of intertrochanteric fracture of the femur using sliding screw plate fixation. 163: 148-158.

12. Haentjens P, Casteleyn P, and Opdecam PB (1985): The Vidal-Goalard megaprosthesis. An alternative to conventional techniques in selected cases?; 51(2): 221. 
13. Steinberg GG, Desai SS, Kornwitz NA, et al. (1988): The intertrochanteric hip fracture: a retrospective analysis; 11(2): 265-273.

14. Rao JP, Banzon MT, Weiss AB, et al. (1983): Treatment of unstable intertrochanteric fractures with anatomic reduction and compression hip screw fixation; 175: 65-71.

15. Lorich DG, Geller DS, and Nielson JH (2004): Osteoporotic pertrochanteric hip fractures: management and current controversies; 86(2): 398-410.

16. Hsu C, et al. (2013): Lateral femoral wall thickness: A reliable predictor of postoperative lateral wall fracture in intertrochanteric fractures; 95(8): 11341138.

17. Tan BY, Lau AC, and Kwek EB (2015): Morphology and fixation pitfalls of a highly unstable intertrochanteric fracture variant; 23(2): 142-145.

18. Videla-Cés M, Sales-Pérez JM, GirósTorres J, et al. (2017): A retrospective cohort study of concomitant ipsilateral extra-capsular and intra-capsular fractures of the proximal femur. Are they casual findings or an undervalued reality?; 48(7): 1558-1564.

19. Mohan R, Karthikeyan R, and Sonanis SJI (2000): Dynamic hip screw: does side make a difference?: Effects of clockwise torque on right and left DHS; 31(9): 697-699.
20. Parker MJ and Handoll HH (2006): Replacement arthroplasty versus internal fixation for extracapsular hip fractures in adults. 2.

21. Kim SY, Kim YG, and Hwang JK (2005): Cementless calcar-replacement hemiarthroplasty compared with intramedullary fixation of unstable intertrochanteric fractures: a prospective, randomized study; 87(10): 2186-2192.

22. Sahoo PK, Dash SK, Panigrahi R, et al. (2015): Cemented bipolar hemiarthroplasty versus proximal femoral nails: a prospective comparative outcome analysis in unstable elderly intertrochanteric fractures. International Journal of Health Sciences and Research; 5(6).

23. Özkayın N, Okçu G, and Aktuğlu KJI (2015): Intertrochanteric femur fractures in the elderly treated with either proximal femur nailing or hemiarthroplasty: a prospective randomised clinical study; 46: S3-S8.

24. Nie B, Wu D, Yang Z, et al. (2017): Comparison of intramedullary fixation and arthroplasty for the treatment of intertrochanteric hip fractures in the elderly: a meta-analysis; 96(27). 


\section{دراسة مقارنة بين التثبيت الاخلي بواسطة المسامير النخاعية وتقويم مفصل الفخذ لعلاج الكسور

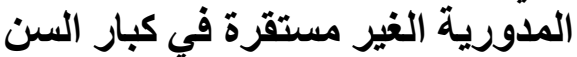 \\ إبراهيم الجنزوري**، أسامة فرج*، عمرو أحمد*، أحمد سالم**، ديفيد جرجس راضي**}

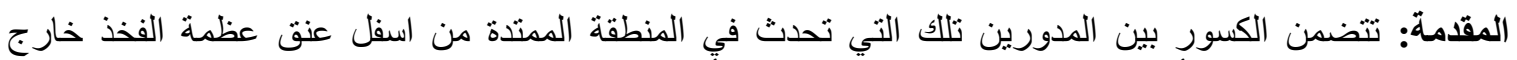
المحفظة إلى منطقة المدور الأصغر ، وهذه الكسور مسؤولة عن أربعين بالمائة من كسور العلي عظمة الفخذ عند كبار

الهذف من العمل: هو مقارنة التثبيت الداخلي باستخدام مسمار نخاعي ورأب مفصل الورك في في علاج كسور ما بين الإنين

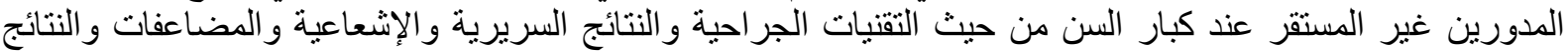
الوظيفية ورضا المريض.

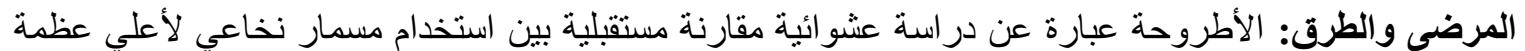

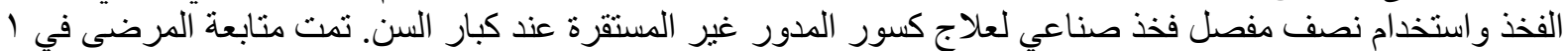

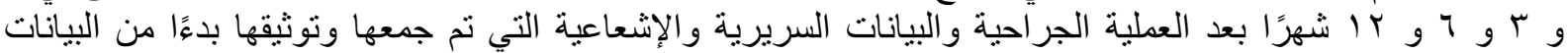
المحيطة بالجر احة (وقت العملية ، وفقدان الدم ، و ونقل الدم).

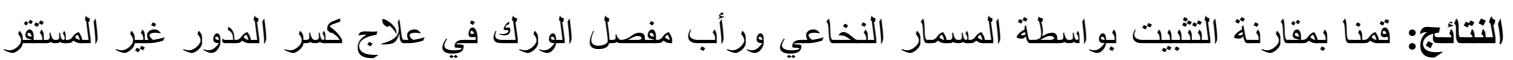

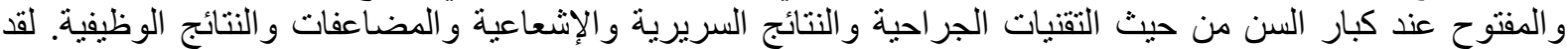

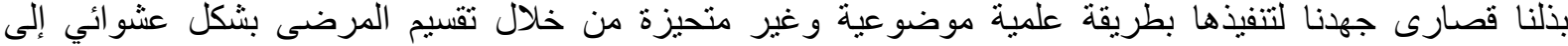

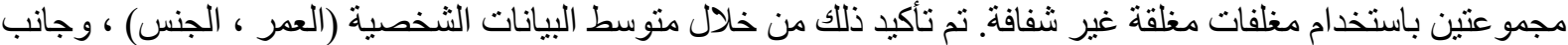

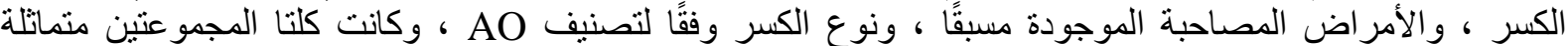

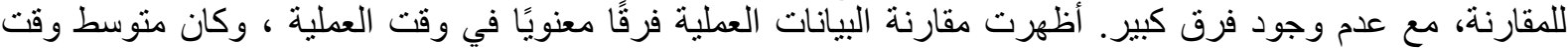

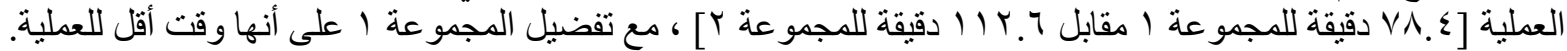

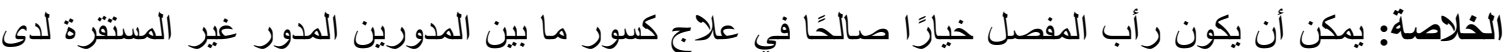

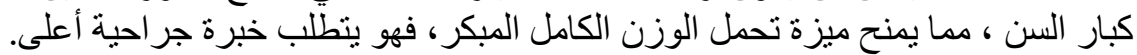

